\title{
REVIEW
}

\section{Difficult asthma}

\author{
P.J Barnes*, A.J Woolcock**
}

Difficult asthma. P.J Barnes, A.J Woolcock. OERS Journals Ltd 1998.

ABSTRACT: Asthma is usually easy to manage, but $\sim 5 \%$ of patients are not controlled even on high doses of inhaled corticosteroids. It is important to assess these patients carefully in order to identify whether there are any correctable factors that may contribute to their poor control. It is critical to make a diagnosis of asthma and to exclude other airway diseases, particularly chronic obstructive pulmonary disease (COPD), and vocal cord dysfunction ("pseudo-asthma"). Poor adherence to therapy, particularly inhaled corticosteroids, is a common reason for a poor response. There may be unidentified exacerbating factors, including unrecognized allergens, occupational sensitizers, dietary additives, drugs, gastro-oesophageal reflux, upper airway disease, or other systemic diseases, that need to be identified and avoided or treated. Psychological factors may be important in some patients, but it is difficult to know whether these are causal or secondary to troublesome disease. Some patients have instability of their asthma, with resistant nocturnal asthma, premenstrual exacerbations or chaotic and unpredictable instability (brittle asthma). A few patients are completely resistant to corticosteroids, but more patients are relatively resistant and require relatively high doses of corticosteroids to control their symptoms (steroiddependent). Some patients develop progressive loss of lung function, as in patients with COPD. Management of patients with difficult asthma should be supervised by a respiratory specialist and should involve careful assessment to confirm a diagnosis of asthma, identification and treatment of exacerbating factors, particularly allergens, and recording of peak expiratory flow patterns. A period of hospital admission may be the best way to assess and manage these patients. Treatment involves optimizing corticosteroids therapy, assessing additional controllers such as long-acting inhaled or subcutaneous $\beta_{2}$-agonists or subcutaneous, theophylline and antileukotrienes. In some patients, the use of immunosuppressive treatments may reduce steroid requirements, although these treatments are rarely effective and have side-effects. In the future, the nonsteroid anti-inflammatory treatments now in development may be useful in these patients.

Eur Respir J 1998; 12: 1209-1218.

Most patients with asthma are easily diagnosed and respond to standard treatment with a short-acting inhaled $\beta_{2}$ agonist for symptom control and long-term treatment with an inhaled corticosteroid in doses of up to $2,000 \mu \mathrm{g}$ daily. Approximately $5 \%$ of patients do not respond to this regime and require further investigation to establish the reasons for the lack of response. "Difficult asthma" may be defined as failure to achieve control when maximally recommended doses of inhaled therapy are prescribed. Although difficult asthma is usually severe, as judged by the need for extensive treatment, it may not necessarily be so as some patients have severe exacerbations but are well controlled most of the time.

There are several factors that may contribute to a poor response to conventional therapy. It is important to consider these reasons systematically (table 1 ). Many patients with severe asthma are undertreated; in a recent survey, over $60 \%$ of patients classified as having severe asthma were not even treated with anti-inflammatory therapy [1]. All patients classified as suffering from difficult asthma should be assessed by a respiratory specialist, preferably in a specialist clinic devoted to patients with difficult asthma. Since patients with difficult asthma account for a
*Dept of Thoracic Medicine, National Heart and Lung Institute, Imperial College, London, UK. **Institute of Respiratory Medicine, Royal Prince Alfred Hospital and University of Sydney, Australia.

Correspondence: P.J. Barnes

Dept of Thoracic Medicine

National Heart and Lung Institute

Dovehouse St

London SW3 6LY

UK

Fax: 441713515675

Keywords: Adherence

brittle asthma

corticosteroid-resistance

gastro-oesophageal reflux

premenstrual asthma

pseudo-asthma

Received: June 191998

Accepted for publication July 81998 large proportion of the direct and indirect costs of asthma, referral is financially as well as clinically justifiable [2].

\section{Incorrect diagnosis}

In some patients, an incorrect diagnosis of asthma results in an apparent failure to respond to conventional antiasthma therapy. Several diseases may cause wheezing, including left ventricular failure, chronic obstructive pulmonary disease (COPD) or localized obstruction of a major airway. COPD is usually easy to distinguish from asthma, by its slowly progressive course and association with longstanding cigarette smoking, but sometimes the distinction from late onset asthma, particularly in cigarette smokers, may be difficult. In these patients, a trial of oral corticosteroids is indicated; this involves administration of oral prednisone/prednisolone (30-40 $\mathrm{mg}$ in the morning) for 14 days. An increase in forced expiratory volume in one second (FEV1) or peak expiratory flow (PEF) of $>15 \%$ indicates asthma. A negative response may indicate COPD, or rarely corticosteroid-resistant asthma (which shows the characteristic bronchodilator response of asthma), or simply a failure to adhere to the course of oral corticosteroids. 


\section{Table 1. - Difficult asthma}

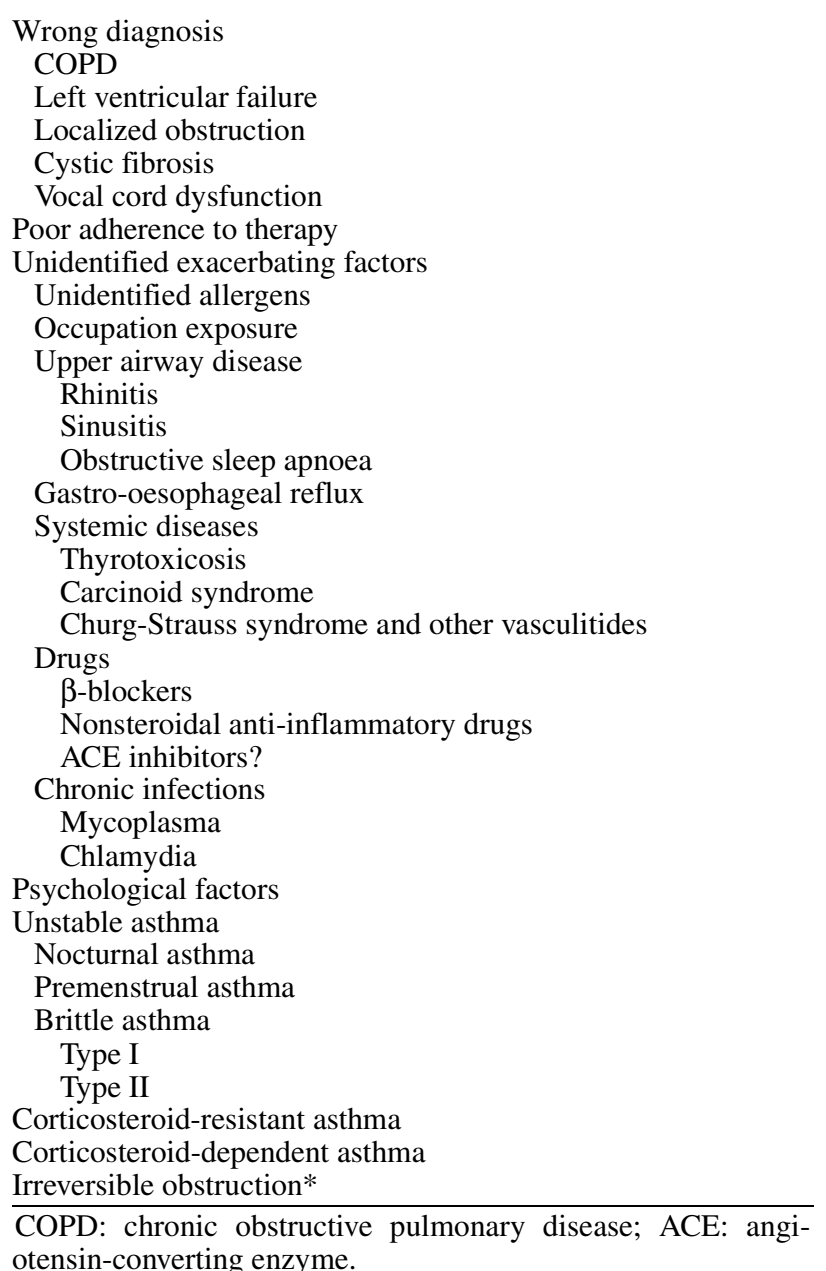

One study using phenobarbitone as a marker of compliance showed that $26 \%$ of patients in a corticosteroid trial failed to take the tablets and could have been classified as nonresponsive [3]. In children, several diseases may present with wheezing, including cystic fibrosis and acute viral bronchiolitis.

It is important to consider the possibility that other diseases are causing wheezing. Because the diagnosis is usually obvious if a careful history is taken, and the presence of reversible airflow limitation confirmed by appropriate investigations.

\section{Vocal cord dysfunction}

Vocal cord dysfunction ("pseudo-asthma") is often misdiagnosed as asthma. It is due to upper airway obstruction caused by adduction of the anterior two-thirds of the vocal cords, leaving only a 4-5-mm posterior "chink", resulting in upper airway obstruction $[4,5]$. This is likely to be a hysterical conversion syndrome with secondary gain from the diagnosis of a chronic disabling disease. In a recent series of such patients, $32 \%$ had coexistent asthma, which complicates the diagnosis [5]. Some of these patients may be treated with large doses of antiasthma therapy, including oral corticosteroids and immunosuppressive therapy, and may even be classified as having corticosteroid-resist- ant asthma [6, 7]. The wheezing in these patients is never present during sleep and often worsens during examination of the chest.

Forced expiratory tracings often show suboptimal effort with variable responses, and a flow-volume curve indicates reduced inspiratory flow. Despite low recorded values of FEV1 and PEF, plethysmographic measurements of airways resistance are usually normal. When forced expiration is reduced out of proportion with the increase in airways resistance, this may be due to coexistent asthma. Direct examination of the vocal cords by laryngoscopy shows the characteristic adduction of the vocal cords in association with wheezing $[5,8]$. Some patients who present with cough and wheeze have an increased reactivity of the extrathoracic airway to inhaled histamine measured by a flow-volume loop; some of these patients have asthma (airway hyperresponsiveness) and others do not [9]. Patients with increased extrathoracic sensitivity to histamine are more likely to present as cough than wheeze and have associated chronic diseases of the upper respiratory tract, particularly chronic sinusitis and postnasal drip.

Management of vocal cord dysfunction is difficult, and direct confrontation is not helpful. It is important to withdraw oral and inhaled corticosteroids, but it may be useful to continue inhaled $\beta_{2}$-agonists on an "as-required" basis. Psychiatric assessment is rarely useful, but speech therapy can be helpful in some patients. Hypnotherapy and neurofeedback training have also been reported to be successful in some patients [8].

The natural history of this condition is pessimistic, and the patients frequently revert to antiasthma therapy. In three patients followed over $10 \mathrm{yrs}$, the condition persisted in two patients who continued antiasthma therapy and there was a response in one patient only after bypassing the upper airway with tracheostomy [10].

\section{Poor adherence}

One of the commonest reasons for a poor response to asthma therapy is the failure to take the prescribed treatment correctly $[11,12]$. Poor adherence is surprisingly common, and a recent study that measured compliance with a computerized timing device in a dry-powder inhaler showed that only $18 \%$ of patients took inhaled corticosteroids as prescribed [13]. Another study of an inhaled anticholinergic in a clinical trial showed similar poor compliance when a computerized timing device was used (15\% adherence) and demonstrated that canister weighing overestimated compliance [14]. It is likely that poor compliance with inhaled corticosteroids results from a lack of immediate beneficial effect on asthma symptoms and an unwarranted fear of side-effects. Many patients with poorly controlled asthma who are admitted to hospital show rapid improvement when the previously prescribed medication is given under supervised conditions. Monitoring of compliance is difficult in clinical practice as monitoring has demonstrated that many patients "dump" the doses before attending the outpatient clinic when the inhaler will be weighed or the number of activations recorded [13, 14]. Over the longterm, monitoring of the number of prescriptions filled may be a useful way of assessing the amount of medication used and is facilitated by computerized recording of prescriptions in some countries. 
Adherence may be better with tablets than with inhalers, and one study showed a significantly better compliance with oral theophylline than with inhaled corticosteroids [15]. However, more studies are needed to determine the factors that contribute to poor compliance. Adolescent patients are particularly poor at complying with regular therapy, as they are resentful about the need for therapy and may be unduly concerned about side-effects. Compliance may be improved by education, although this has yet to be demonstrated convincingly in controlled studies. Combination therapy with an inhaled $\beta_{2}$-agonist and corticosteroid may improve compliance as the bronchodilator effect of the inhaled $\beta_{2}$-agonist may increase the overall compliance. Indeed, a fixed combination inhaler of terbutaline and budesonide gave a better control of asthma than either treatment alone [16], and may be a useful strategy for some patients, particularly when fixed combinations of a longacting $\beta_{2}$-agonist and a corticosteroid (salmeterol + fluticasone or formoterol + budesonide) become available. For patients who are noncompliant with oral corticosteroids, it may be necessary to use an intramuscular preparation such as triamcinolone acetonide, which may improve control in some patients with severe life-threatening asthma [17].

\section{Unidentified exacerbating factors}

Asthma may remain difficult to control if exacerbating factors persist, and it is important to identify and eliminate these whenever possible.

\section{Unidentified allergens}

Inhaled allergens are important in driving asthmatic inflammation, and exposure to high levels of allergen may be an important factor in patients with severe asthma that is not readily controlled. It is important to introduce strict allergen-avoidance procedures for such patients. The most common domestic allergens are house dust mite and cats, but exposure to other allergens, including cockroaches, domestic pets and mould spores should be considered. Some severe exacerbations of asthma may be precipitated by aeroallergens such as mould spores [18].

Some patients have been described with severe asthma that appears to be due to an allergic reaction to the skin fungal infection trychophyton and responds to eradication of the infection with antifungal agents [19]. These patients have negative skin reactions to common aeroallegens and would be classified as having nonatopic asthma. Whether this phenomenon applies to other fungal infections has not yet been established.

\section{Occupational exposure}

There are many chemical sensitizers to which patients are exposed at work [20], and it is important to consider an occupational history, particularly when asthma improves at weekends and on holiday. It is particularly important to make the diagnosis of occupational asthma early so that appropriate avoidance measures can be instituted. Exposure to the causative agent for more than 6 months may be associated with the persistence of asthma, even when avoidance is complete.

\section{Dietary factors}

Patients commonly believe that dietary constituents may worsen asthma, but there is little objective evidence that chronic asthma is worsened by allergic responses to normal dietary components. Food additives, such as sodium metabisulphite and tartrazine, may cause wheezing and should be avoided [21]. Dietary salicylates may worsen asthma in certain patients and salicylate-free diets may result in improvement in asthma. Monosodium glutamate, a previously frequent additive in Chinese meals, has been associated with wheezing, but this is very uncommon [22]. Dietary factors may cause an acute anaphylactic response, which may be mistaken for brittle asthma (see below).

\section{Drugs}

Asthma may be exacerbated by ingestion of certain drugs, including nonsteroidal anti-inflammatory drugs and $\beta$-blockers [23].

Aspirin-sensitive asthma (ASA) is relatively common in some areas, such as Eastern Europe and Japan, but is rare in Western Europe, USA and Australasia, so may be overlooked. ASA is often preceded by rhinitis and nasal polyps. Attacks are precipitated by aspirin and other nonsteroidal anti-inflammatory drugs, and may be severe [24]. There is evidence for increased production of cysteinylleukotrienes [25] and overexpression of leukotriene (LT) $\mathrm{C}_{4}$ synthase, predominantly in eosinophils in bronchial biopsies [26]. ASA is more frequently associated with a genetic polymorphism in the promoter sequence of $\mathrm{LTC}_{4}$ synthase that is associated with increased enzyme expression [27]. ASA is effectively blocked with antileukotrienes $[28,29]$ and these drugs may be the optimal treatment for these patients [30].

$\beta$-Blockers are well recognized to precipitate exacerbations of asthma that may occasionally be fatal, but patients with asthma are still given $\beta$-blockers inadvertently. The worsening of asthma is due to blockage of $\beta_{2}$-adrenoceptors, but even $\beta_{1}$-selective blockers, such as atenolol, bisoprolol and metoprolol, are dangerous, since they are not completely selective. $\beta$-Blocker eye-drops, such as timolol, used for the treatment of glaucoma, are also dangerous since some patients may be extremely sensitive to these drugs. The mechanism of $\beta$-blocker induced asthma is not completely understood, but may in part be due to increased cholinergic bronchoconstriction and may be reversed with anticholinergic drugs [31]. All $\beta$-blockers should be avoided in asthmatic patients and alternative therapies, such as calcium antagonists and $\alpha$-blockers used to treat ischaemic heart disease and hypertension.

There is no evidence that the well recognized cough associated with angiotensin-converting enzyme (ACE) inhibitors, such as captopril and enalapril, is more common in patients with asthma. It is not certain whether ACE inhibitors may worsen asthma. A retrospective cohort study suggested that bronchospasm was twice as common in patients treated with ACE inhibitors compared to the reference group treated with lipid lowering drugs [32]. There was some evidence that bronchoconstriction was more common in patients with cough. In a controlled trial in asthmatic and hypertensive patients (with and without cough), there was no change in lung function following administration of captopril and no increase in reactivity to histamine or bradykinin [33], and similar findings were obtained 
in a group of asthmatic patients given ACE inhibitors for 3 weeks, although one subject (out of 21) developed increased wheezing [34]. This suggests that ACE inhibitors are unlikely to worsen asthma in the majority of patients, although there may be occasional patients in whom this occurs. When there is a possibility that asthma has been worsened or precipitated by an ACE inhibitor, the drug should be withdrawn and an alternative agent selected.

\section{Gastro-oesophageal reflux}

Gastro-oesophageal reflux is more common in patients with asthma than in the general population, with an estimated prevalence of $34-80 \%[35,36]$. It has been estimated that approximately one-third of patients who suffer from gastro-oesophageal reflux-related asthma may have silent reflux [35]. Reflux may be due to transient relaxation of the gastro-oesophageal sphincter, as a result of bronchodilator therapy, flattening of the diaphragm due to air trapping and raised intra-abdominal pressures [37, 38]. Gastro-oesophageal reflux may cause unexplained cough, but may also lead to exacerbation of asthma and may increase asthma symptoms [39]. This may be due to activation of an oesophageal vagal reflex via cholinergic pathways or to reflux of stomach contents with microaspiration. Continuous monitoring of $\mathrm{pH}$ suggests that the reflex theory is more likely as patients with asthma usually have acidification of the distal, rather than the proximal, oesophagus, whereas patients with noncardiac chest pain usually have proximal reflux [40]. There may be improvement with anticholinergic therapy [41]. However, in a study of four patients in whom simultaneous measurements of oesophageal and tracheal $\mathrm{pH}$ were made, episodes of airway narrowing correlated with lowering of tracheal $\mathrm{pH}$, indicating microaspiration [42].

If oesophageal reflux is suspected, measures should be taken to reduce reflux and a trial of therapy with the proton pump inhibitors (omeprazole, lansoprozole, pantoprazole) should be undertaken. Patients with gastro-oesophageal reflux may require higher than conventional doses for a prolonged period. However, response to this therapy is usually disappointing, suggesting that gastro-oesophageal reflux is unlikely to be an important mechanism of worsening of asthma, even when marked reflux has been demonstrated [43].

\section{Upper airway disease}

The role of upper airway inflammation in exacerbating asthma is often overlooked. Allergic rhinitis is common in patients with asthma and may contribute to poor control. Treatment of allergic rhinitis with nasal corticosteroids improves airway hyperresponsiveness, indicating a link between upper and lower airway inflammation [44]. Treatment of symptomatic rhinitis should always be considered when asthma remains poorly controlled.

Sinus disease may also predispose persons to poor asthma control. Surgical treatment of sinus disease may improve asthma control [45].

The mechanisms whereby upper airway disease can worsen asthma are poorly understood. Naso-bronchial neural reflexes have been described, but it is unlikely that they contribute to long-standing worsening of asthma control. Experimental sinusitis in rabbits leads to an increased airway hyperresponsiveness that is not seen when the animals are kept "nose down", suggesting that post-nasal drip may be important [46], possibly in delivering cytokines to the lower airways. Another possible explanation is that inflammatory mediators in post-nasal drip result in extrathoracic hyperresponsiveness, resulting in cough [9].

Obstructive sleep apnoea and snoring also appear to aggravate asthma so that it is more difficult to control, possibly because of increased inhaled allergens or decreased humidity of inspired air when the upper airways are bypassed. In such patients, treatment with nasal positive pressure at night can improve control [47].

\section{Other diseases}

Surprisingly few concomitant diseases worsen asthma control, presumably because asthma is localized to the airways.

Thyrotoxicosis causes worsening of asthma, although the mechanisms are uncertain. Since hyperthyroidism is associated with an increased sympathetic drive, this might be expected to reduce asthma symptoms. Asthma improves with treatment of thyrotoxicosis [48]. The worsening of asthma may be related to an interaction between thyroid hormone receptors and glucocorticoid receptors, resulting in reduced effects of corticosteroids.

Carcinoid syndrome with hepatic metastases is a very rare cause of worsening of asthma, due to the release of bronchoconstrictor peptides, such as bombesin and kinins, from the hepatic secondaries [49].

Churg-Strauss syndrome is a rare vasculitic syndrome in which asthma is associated with systemic vasculitis and eosinophilia [50]. Asthma may be severe and difficult to control with inhaled corticosteroids. A very high eosinophil count and features of vasculitis, such as peripheral neuropathies, renal dysfunction and cardiac arrhythmia, should be warning signs. Recently, patients with ChurgStrauss syndrome associated with the introduction of zafirlukast have been reported, but these cases appear to be related to a reduction in systemic corticosteroids after the introduction of the antileukotriene [51].

\section{Respiratory tract infections}

Several studies have highlighted the importance of virus infections in precipitating acute severe exacerbations of asthma [52]. There is some evidence that Mycoplasma pneumoniae may be found in patients with more severe asthma and could act as a perpetuating mechanism [53]. Treatment with clarithromycin resulted in an improvement in asthma symptoms and airway wall inflammation. In children, persisting infection with Chlamydia pneumoniae has been associated with more frequent exacerbations of asthma [54] and might be another infection that worsens asthma. Chronic chlamydia infection has been reported in some patients with severe corticosteroid-dependent asthma with improvement after treatment with clarithromycin or azithromycin [55]. Treatment with macrolide antibiotics may therefore have some potential in the management of patients with difficult asthma and needs to be evaluated in controlled trials. 


\section{Psychological factors}

In many patients with difficult asthma psychological factors may play a role [56]. It is difficult to separate whether having difficult and, in some cases, life-threatening asthma makes patients psychologically unstable, or whether psychiatric abnormalities worsen asthma control. In a survey of patients with near-fatal asthma, over $50 \%$ were found to have significant psychological abnormalities [57].

Stress is a well-known asthma trigger, but there is no evidence that stress itself causes asthma. The marked placebo response seen in some patients indicates that psychological factors have a profound effect on asthma, and it is likely that they contribute to poor control of the disease in some patients. Psychological factors may be associated with poor adherence with asthma therapy, although there are no obvious personality traits that have been identified in poor compliers. Depression, anxiety and problems with interpersonal relationships reduce adherence with therapy [58]. Many patients with brittle asthma have psychological problems, but this may result from the unpredictable nature of severe exacerbations.

\section{Unstable asthma}

In some patients, asthma may be difficult to control despite adequate therapy.

\section{Nocturnal asthma}

Nocturnal asthma is the commonest pattern of instability and is usually an indicator of suboptimal treatment. Sometimes, nocturnal asthma persists despite treatment with maximal doses of inhaled corticosteroids and long-acting inhaled $\beta_{2}$-agonists or slow-release theophylline. Sometimes, these patients respond well to a subcutaneous infusion of a short acting $\beta_{2}$-agonist (salbutamol, terbutaline) overnight.

\section{Premenstrual asthma}

Premenstrual worsening of asthma may occur in some females. Although premenstrual exacerbation of asthma may be mild and may respond to an increased dose of inhaled corticosteroids, it may be particularly severe in some patients and appears to be corticosteroid resistant. Occasional patients will require hospital admission and even ventilation every month [59]. The characteristic pattern is of increased asthma symptoms and a fall in PEF 2-5 days before the menstrual period, with improvement once menstruation begins. There is no association with symptoms of premenstrual tension, and it is unclear why this pattern is only seen in a proportion of females. Airway hyperresponsiveness increases premenstrually, and it is assumed that this increase is greater in females who are symptomatic [60].

The mechanisms of premenstrual symptoms are uncertain. The timing of the asthma exacerbation coincides with a fall in progesterone secretion and a rise in the oestrogen:progesterone ratio. This suggests that progesterone normally exerts a protective, possibly anti-inflammatory, effect in these patients. Progesterone receptors, like glucocorticoid receptors, directly interact with the transcription factor nuclear factor- $\kappa \mathrm{B}(\mathrm{NF}-\kappa \mathrm{B})[61]$. NK- $\kappa \mathrm{B}$ appears to be a key transcription factor that orchestrates asthmatic inflammation, and therefore, a fall in progesterone would tend to increase asthmatic inflammation. Why this should only produce worsening of asthma in a proportion of females is unclear, but it may be related to their sensitivity to corticosteroids. Premenstrual asthma is poorly responsive to increased inhaled or oral corticosteroids, indicating a degree of corticosteroid resistance in these patients. Since glucocorticoids also block NF- $\mathrm{KB}$, this may indicate that there is excessive NF- $\kappa \mathrm{B}$ formation in these patients. Another possibility is that there is an abnormality in $\beta$ receptor function. There is a premenstrual reduction in $\beta_{2}$-receptor density on circulating lymphocytes, suggesting that the bronchodilator response to inhaled $\beta_{2}$-agonists may be impaired in patients with premenstrual asthma [62].

Management of premenstrual asthma symptoms may be difficult. As discussed above, these patients are poorly responsive to glucocorticoids. Progesterone appears to be effective, but only when large doses are given parenterally [59]. Oral progesterone appears to be ineffective, and it is recommended that patients are treated with a intramuscular progestogen (such as DepoProvera) during the week before menstruation. Unfortunately, this may lead to fluid retention and depression in some patients. Gonadotrophin-releasing hormone analogues, such as goserelin or buserelin, which increase progesterone concentrations, are an alternative approach. Occasionally, premenstrual asthma is so severe that it can only be controlled by surgical removal of the ovaries.

\section{Brittle asthma}

Brittle asthma refers to unstable asthma that is unpredictable, and often no consistent trigger factors can be identified. Brittle asthma is rare and may occur in only $0.05 \%$ of all asthmatics, although these patients present considerable management problems. There are two patterns of brittle asthma [63]. Type I: persistent and chaotic variability in PEF (usually $>40 \%$ diurnal variation in PEF for $>50 \%$ of time) despite considerable medical therapy, and type II: sporadic sudden falls in PEF on a background of normal or near normal lung function and well-controlled asthma.

In type I brittle asthma there are usually no identifiable trigger factors that are related to the falls in PEF. Many of the patients have psychological problems and there may be problems of adherence with therapy.

In type II brittle asthma, there may be rapid and unexpected falls in PEF with severe exacerbations that may require ventilation. Some of these patients may have a problem with perception of disease severity. In patients who had suffered sudden onset near-fatal asthma attacks, there was impaired perception of airway narrowing and a reduced ventilatory response to hypoxia $[64,65]$. This suggests that such patients may not be aware of the severity of attacks and therefore delay taking appropriate preventive or reliever therapy [66]. Patients with type II brittle asthma often respond poorly to nebulized bronchodilators, suggesting that there may be a component of airway narrowing that is not due to airway smooth muscle contraction. It is possible that this may be explained by an acute oedematous swelling of the airway. There is some 
evidence that patients with type II brittle asthma have a high incidence of food allergy [67] and reported food allergy is a risk factor in death and near death from asthma [68]. It is possible that type II brittle asthma may therefore represent an airway anaphylactic response that is triggered by food.

Management of type I brittle asthma is difficult, as these patients often fail to respond to conventional therapy. Patients with type I brittle asthma who have persistent variability in PEF often fail to respond to inhaled long-acting $\beta_{2}$-agonists or repeated nebulized $\beta_{2}$-agonists and anticholinergics. Subcutaneous infusions of $\beta_{2}$-agonists (salbutamol or terbutaline) may be very helpful in some patients, particularly in controlling nocturnal symptoms [69]. The $\beta_{2}$-agonist is usually given via an insulin infusion pump, and the lowest dose that controls symptoms is selected (usually terbutaline 3-12 $\mathrm{mg}$ in $24 \mathrm{~h}$ ). Side-effects may be a problem. The most troublesome adverse effect is muscle cramps, associated with elevated levels of total serum creatinine kinase, which are often dose limiting [70].

Treatment of type II brittle asthma is even more difficult, as these patients often have normal or near normal lung function for most of the time. It is not certain whether vigorous preventive therapy is effective in these patients. The possibility of food allergy should be considered. In a preliminary report, food intolerance was identified by doubleblind challenge in $6 / 8$ patients with brittle asthma who went on to improve with an exclusion diet [71]. Treatment of acute exacerbations should involve immediate administration of a bronchodilator. Because of the rapidity of the attacks, bronchodilator therapy is best given by injection, and because of the possibility that anaphylaxis is involved, adrenaline (epinephrine) is the bronchodilator of choice. Patients should always carry preloaded adrenaline syringes (e.g. Epi-pen, Mini-jet) and relatives or close associates should be instructed in giving these injections. Patients should also carry some type of warning, such as a Medic-Alert bracelet.

\section{Corticosteroid-resistant asthma}

Response to glucocorticoids is the hallmark of asthma, but there are some patients in whom corticosteroids are ineffective. True corticosteroid-resistant asthma is very uncommon and may occur in only 1 in 1,000 to 1 in 10,000 asthmatic patients $[72,73]$. It is important to establish the diagnosis carefully with a formal trial of corticosteroids. This is recommended to be oral prednisolone $30-40 \mathrm{mg}$ daily in a single morning dose for 2 weeks. This should be preceded by a 2-week period of monitoring, ideally with placebo tablets. Corticosteroid resistance is diagnosed if the increase in FEV1 or mean PEF is $<15 \%$ above baseline values. It is important to exclude airway obstruction due to COPD. In contrast to patients with COPD, patients with corticosteroid-resistant asthma have bronchodilator responses of $>15 \%$ and spontaneous variability in PEF [73]. Bronchial biopsy studies have demonstrated that these patients, like corticosteroid-sensitive asthmatic patients, also have an eosinophilic infiltration and express similar T-helper (Th)2 cytokines [74].

The molecular mechanisms of corticosteroid-resistant asthma have recently been established, and the mechanisms may differ from patient to patient $[75,76]$. The majority of patients have normal plasma cortisol concentrations and do not suffer from adrenal insufficiency, suggesting that the metabolic and endocrine functions of endogenous glucocorticoids are unimpaired. The defect appears to be in the anti-inflammatory action of corticosteroids and, whereas there are usually no abnormalities in binding of glucocorticoids to glucocorticoid receptors, there is an impaired interaction between glucocorticoid receptors and deoxyribonucleic acid (DNA), which appears to be secondary to an abnormality between the glucocorticoid receptor and the transcription factor activator protein-1 (AP-1) [77, 78]. Indeed, there is an increased basal and stimulated activation of AP-1 in these patients, suggesting that this transcription factor may consume glucocorticoid receptors via a direct protein-protein interaction, thus reducing the antiinflammatory effect of glucocorticoids. There is increased activation of AP-1 by cytokines, and this appears to be due to excessive activation of the key enzyme Jun kinase [79].

Management of these patients is problematic in view of their failure to respond to corticosteroids $[75,80]$. Indeed, treatment with glucocorticoids should be discontinued, as these patients do develop systemic side-effects to corticosteroids (presumably mediated via the normally functioning endocrine and metabolic pathways) [81]. Long-acting inhaled $\beta_{2}$-agonists may be useful in these patients. Theoretically, immunosuppressants, such as methotrexate and cyclosporin A, may be useful in these patients, but in our experience, they appear to provide little benefit and often have unacceptable side-effects.

\section{Corticosteroid-dependent asthma}

Corticosteroid-dependent asthma is defined as asthma that can only be controlled with oral corticosteroids. By definition, it is severe, but is differentiated from corticosteroid-resistant asthma by the fact that there is a response to corticosteroids, although only when high doses are given. Lowering the maintenance dose of inhaled corticosteroids results in worsening asthma control. This suggests that these patients are relatively resistant to the anti-inflammatory effects of corticosteroids and may be part of a continuum, with corticosteroid-resistant asthma at one extreme.

The mechanisms of relative corticosteroid resistance are not yet certain, as these patients are difficult to investigate with invasive techniques. Patients with steroid-dependent asthma showed activated eosinophils, T-lymphocytes and interleukin (IL)-5 immunoreactivity in their bronchial biopsies, although to a greater extent than in mild asthma $[82,83]$. Recent studies with bronchial biopsy, bronchoalveolar lavage and induced sputum have shown that inflammation persists, despite high doses of corticosteroids, and there is an increase in neutrophils in the airways of these patients $[84,85]$, but whether this contributes to the pathophysiology or whether it reflects high dose steroid treatment (as corticosteroids increase neutrophil survival) is not yet certain. It is possible that these patients develop corticosteroid resistance secondary to asthmatic inflammation. The pro-inflammatory cytokines, IL-1 $\beta$ and tumour necrosis factor (TNF)- $\alpha$, activate the transcription factors $\mathrm{AP}-1$ and NF- $\kappa \mathrm{B}$, which then bind to glucocorticoid receptors, thus reducing the number of receptors available for activation by glucocorticoids. It is possible to demonstrate this mechanism of resistance both in vitro and in vivo $[86,87]$. Treatment with very high doses of corticosteroids might overcome this resistance, and once the proinflammatory transcription factors have been blocked, the 
glucocorticoid receptors will be available, restoring glucocorticoid sensitivity. In treating severe asthma, it is rational to start with high doses of corticosteroids (induction phase), with reduction to lower doses to maintain control (maintenance phase). Pulse therapy with high doses of corticosteroids (such as systemic methylprednisolone) may therefore be considered in these patients in order to reestablish corticosteroid sensitivity.

Another possible mechanism for corticosteroid resistance may be the effect of high doses of inhaled $\beta_{2}$-agonists. In vitro high concentrations of $\beta_{2}$-agonists may interfere with the actions of glucocorticoids by activating the cyclic adenosine monophosphate response element binding (CREB) protein transcription factor, which interacts directly with the glucocorticoid receptor, in the same manner as AP-1 and NF- $\mathrm{NB}$. This interaction had been demonstrated in lung tissue, T-lymphocytes, and epithelial cells [88, 89], and predicts that high doses of inhaled $\beta_{2}$-agonists result in relative corticosteroid resistance. When patients treated with very high doses of inhaled $\beta_{2}$-agonists are weaned to low doses, there is evidence for a reduced requirement for oral corticosteroids [90,91], and this strategy should be considered in all patients thought, or known, to be taking large doses of $\beta_{2}$-agonists.

\section{Irreversible obstruction}

Although asthma is a reversible disease, progressive airflow obstruction is seen in some patients $[92,93]$. The annual rate of decline in lung function is increased in asthmatic patients to the same degree as in cigarette smokers [94]. This irreversible narrowing of the airways only appears to occur in some patients and usually in those with most severe disease, but at the moment, there is no way of predicting which patients will show the greatest decline. The nature of the airway obstruction in these patients is not yet known, but is presumed to be due to structural changes in the airways, such as fibrosis and thickening of airway smooth muscle, which are a consequence of uncontrolled chronic airway inflammation. However, subepithelial fibrosis is found even in patients with mild episodic asthma and does not appear to be increased even in corticosteroid-dependent asthmatic patients [95]. Highresolution computed tomography scans have demonstrated an increase in emphysema and bronchiectasis in patients with more severe asthma, particularly when it is nonallergic [96]. It is possible that some of the proteolytic enzymes released from inflammatory cells in the airways of asthmatic patients, such as matrix metalloproteinases, may account for these structural changes. Structural changes are presumed to be irreversible using currently available therapies, and this emphasizes the need for early and effective control of the inflammatory process. There is increasing evidence that the early use of inhaled corticosteroids may prevent irreversible changes in airway function [97$100]$, but more controlled studies are needed.

Some patients will have both asthma and COPD as both diseases are common and may have a common underlying predisposition. The asthmatic component of the disease is revealed using a formal trial of oral corticosteroids. Management of such patients may involve treatment with bronchodilators (combination of inhaled $\beta_{2}$-agonists and anticholinergic) and the use of corticosteroids.

\section{The practical approach to the management of difficult} asthma

When confronted with a patient in whom asthma appears to be difficult to control with inhaled $\beta_{2}$-agonists and high-dose inhaled corticosteroids, it is important to adopt a logical approach (table 2): 1) It is critical to establish the diagnosis of asthma, and in particular to exclude COPD and vocal cord dysfunction, using appropriate physiological tests and a formal trial of corticosteroids if necessary. 2) It is important to then establish whether the patient is compliant with therapy by direct questioning and by monitoring inhaler and tablet usage, by direct counting or from filled prescriptions. It is also important to check correct usage of inhalers. It may be necessary to admit patients to hospital to determine whether supervised therapy results in better control. 3) Exacerbating factors should be vigorously sought by careful questioning and appropriate investigation. These should then be corrected, where possible, with careful monitoring of asthma. Allergen avoidance may be particularly important in some patients. 4) Unstable as-thma should be carefully assessed with peak flow monitoring and appropriate therapy instituted. The corticosteroid requirement of patients with severe asthma should be de-termined. 5) A period of hospital admission is desirable, as it is then possible to administer medication under sup-ervised conditions, and it is possible to make a more de-tailed assessment of the patient, which may include analysis of induced sputum, fibreoptic bronchial biopsy, a high-resolution computed tomography scan and detailed lung function tests.

\section{Treatment}

If patients are not controlled on short-acting inhaled $\beta_{2^{-}}$ agonists and high doses of inhaled corticosteroids, control may be improved by adding a long-acting inhaled $\beta_{2}$-agonist (salmeterol or formoterol), theophylline or an antileukotriene [101-104]. In patients with difficult asthma who

Table 2. - Important questions in management of difficult asthma

Does the patient have asthma?

Steroid trial if doubts about COPD

Lung function at time of symptoms

Bronchial biopsy

Are adequate doses of steroids reaching the airways? Compliance

Inhaler technique

Have all provoking stimuli been removed from the daily environment of the patient?

Domestic allergens

Occupational sensitizers

Have all potential aggravating factors been removed?

Gastro-oesophageal reflux

Upper airway disease

Obstructive sleep apnoea

Drugs: $\beta$-blockers, nonsteroidal anti-inflammatory drugs, ACE inhibitors?

High doses of inhaled $\beta$-agonists?

Has the patient followed a strict management plan aimed at reducing the severity for disease for at least 6 months?

COPD: chronic obstructive pulmonary disease; ACE: angiotensin-converting enzyme. 
require maintenance oral corticosteroids, the lowest possible dose should be used. Various steroid-sparing treatments have been investigated in an attempt to reduce the dose of oral steroids [105], and these include methotrexate, gold, cyclosporin A, intravenous gamma-globulin and colchicine. None of these treatments is very effective, and they all have a high prevalence of side-effects. Recent studies indicate that some of the patients with difficult asthma have persistent inflammation in the airway, despite the use of oral corticosteroids. For these patients, more specific anti-inflammatory therapies (such as interleukin-5 antagonists or chemokine receptor (CCR3) antagonists) may be useful in the future [106]. Other patients with difficult asthma appear to have no active inflammation (as measured in biopsies or induced sputum), and their persistent abnormality may be due to an abnormal behaviour of airway smooth muscle that will require a different form of treatment (such as selective potassium channel openers or drugs that interfere with abnormally active signal transduction pathways).

\section{References}

1. Bousquet J, Knani J, Henry C, et al. Undertreatment in a nonselected population of adult patients with asthma. $J$ Allergy Clin Immunol 1996; 98: 514-521.

2. Barnes PJ, Jonsson B, Klim J. The costs of asthma. Eur Respir J 1996; 9: 636-642.

3. Hatton MQF, Allen MB, Vathenen S, Feely MP, Cooke NJ. Compliance with oral corticosteroids during steroid trials in chronic airways obstruction. Thorax 1996; 51: 323-324.

4. Christopher KL, Wood RP, Eckert RC, Blager FB, Raney $\mathrm{R}$, Souhrada JF. Vocal-cord dysfunction presenting as asthma. N Engl J Med 1983; 308: 1566-1570.

5. Newman KB, Mason UG, Schmaling KB. Clinical features of vocal cord dysfunction. Am J Respir Crit Care Med 1995; 152: 1382-1386.

6. O'Connell MA, Sklarew PR, Goodman DL. Spectrum of presentation of paradoxical vocal cord motion in ambulatory patients. Ann Allergy 1995; 74: 341-344.

7. Thomas PS, Geddes DM, Barnes PJ. Pseudo-steroid resistant asthma. Thorax 1998; 53: (in press).

8. Nahmias J, Tansey M, Karetzky MS. Asthmatic extrathoracic upper airway obstruction: laryngeal dyskinesis. $N$ Engl J Med 1994; 9: 616-620.

9. Bucca C, Rolla G, Brussino L, de Rose V, Bugiani M. Are asthma-like symptoms due to bronchial or extrathoracic airway dysfunction? Lancet 1995; 346: 791-795.

10. Hayes JP, Nolan MT, Brennan N, FitzGerald MX. Three cases of paradoxical vocal cord adduction followed up over a 10 year period. Chest 1993; 104: 678-680.

11. Cochrane GM. Compliance and outcomes in patients with asthma. Drugs 1996; 52 Suppl 6: 12-9.

12. Milgrom H, Bender B, Ackerson L, Bowry P, Smith B, Rand C. Noncompliance and treatment failure in children with asthma. J Allergy Clin Immunol 1996; 98: 10511057.

13. Bosley CM, Parry OT, Cochrane GM. Patient compliance with inhaled medication: does combining beta-agonists with corticosteroids improve compliance? Eur Respir $J$ 1994; 7: 504-509.

14. Rand CS, Wise RA, Nides M, et al. Metered-dose inhaler adherence in a clinical trial. Am Rev Respir Dis 1992; 146: $1559-1564$.
15. Kelloway JS, Wyatt RA, Adlis SA. Comparison of patients' compliance with prescribed oral and inhaled asthma medications. Arch Int Med 1994; 154: 1349-1352.

16. Barnes PJ, O'Connor BJ. Use of a fixed combination $\beta_{2^{-}}$ agonist and steroid dry powder inhaler in asthma. Am J Respir Crit Care Med 1995; 151: 1053-1057.

17. Ogirala RG, Aldrich TK, Prezant DJ, Sinnett MJ, Enden JB, Williams MH. High dose intramuscular triamcinolone in severe life-threatening asthma. $N$ Engl J Med 1991; 329: 585-589.

18. O'Hollaren MT, Yunginger JW, Offord KP, et al. Exposure to an aeroallergen as a possible precipitating factor in respiratory arrest in young patients with asthma. $N$ Engl J Med 1991; 324: 359-363.

19. Ward GW, Karlsson G, Rose G, Platts-Mills TAE. Trichophyton asthma: sensitization of bronchi and upper airways to a dermatophyte antigen. Lancet 1989; 1: 859-862.

20. Chan-Yeung M, Malo J. Occupational asthma. $N$ Engl $J$ Med 1995; 333: 107-112.

21. Peroni DG, Boner AL. Sulfite sensitivity. Clin Exp Allergy 1995; 25: 680-681.

22. Allen DH, Delomery J, Baker G. Monosodium L-glutamate induced asthma. J Allergy Clin Immunol 1987; 80: 530-537.

23. Barnes PJ. Drug-induced asthma. In: Barnes PJ, Grunstein MM, Leff AR, Woolcock AJ, eds. Asthma. Philadelphia, Lippincott-Raven, 1997; pp. 1245-1252.

24. Szczeklik A. Mechanism of aspirin-induced asthma. Allergy 1997; 52: 613-619.

25. Kumlin M, Dahlen B, Bjorck T, Zetterström O, Granstrom E, Dahlen SE. Urinary excretion of leukotriene $\mathrm{E}_{4}$ and 11dehydro-thromboxane $\mathrm{B}_{2}$ in response to bronchial provocations with allergen, aspirin, leukotriene $\mathrm{D}_{4}$, and histamine in asthmatics. Am Rev Respir Dis 1992; 146: 96-103.

26. Cowburn AS, Sladek K, Soja J, et al. Overexpression of leukotriene $\mathrm{C}_{4}$ synthase in bronchial biopsies from patients with aspirin-intolerant asthma. J Clin Invest 1998; 101: 834-846.

27. Sanak M, Simon HU, Szczeklik A. Leukotriene $\mathrm{C}_{4}$ synthase promoter polymorphism and risk of aspirin-induced asthma. Lancet 1997; 350: 1599-1600.

28. Christie PE, Smith CM, Lee TH. The potent and selective sulfidopeptide leukotriene antagonist SK\&F 104353 inhibits aspirin-induced asthma. Am Rev Respir Dis 1991; 144: 957-958.

29. Israel E, Fischer AR, Rosenberg MA, et al. The pivotol role of 5-lipoxygenase produces in the secretion of aspirin-sensitive asthmatics to aspirin. Am Rev Respir Dis 1993; 148: 1447-1151.

30. Dahlen B, Nizankowska E, Szczeklik A, et al. Benefits from adding the 5-lipoxygenase inhibitor zileuton to conventional therapy in aspirin-intolerant asthmatics. Am J Respir Crit Care Med 1998; 157: 1187-1194.

31. Ind PW, Dixon CMS, Fuller RW, Barnes PJ. Anticholinergic blockade of beta-blocker induced bronchoconstriction. Am Rev Respir Dis 1989; 139: 1390-1394.

32. Wood R. Bronchospasm and cough as adverse reactions to the ACE inhibitors captopril, enalapril and lisinopril. A controlled retrospective cohort study. Br J Clin Pharmacol 1995; 39: 265-270.

33. Overlack A, Muller B, Schmidt L, Scheid ML, Muller M, Stumpe KD. Airway responses and cough induced by angiotensin converting enzyme inhibition. $J$ Human Hypertens 1992; 6: 387-392.

34. Kaufman J, Schmitt S, Barnard J, Busse W. Angiotensinconverting enzyme inhibitors in patients with bronchial responsiveness and asthma. Chest 1992; 101: 922-925. 
35. Simpson WG. Gastroesophageal reflux disease and asthma: diagnosis and management. Arch Intern Med 1995; 155: 798-804.

36. Guill MF. Respiratory manifestations of gastroesphageal reflux in children. $J$ Asthma 1995; 32: 173-189.

37. Pope CE. Acid reflux disorders. N Engl J Med 1994; 331: 656-660.

38. Bechard DE, Schubert ML. Gastroesophageal reflux-induced asthma: new insights. Gastroenterology 1998; 114: 849-850.

39. Field SK, Evans JA, Price LM. The effects of acid perfusion of the esophagus on ventilation and respiratory sensation. Am J Respir Cell Mol Biol 1998; 157: 10581062.

40. Gastal CL, Castell JA, Castell DO. Frequency and site of gastroesophageal reflux in patients with chest symptoms. Chest 1994; 106: 1793-1796.

41. Hervé P, Denjean A, Jian R, Simmoneau G, Duroux P. Intraesophageal perfusion of acid increases the bronchomotor response to methacholine and to isocapnic hyperventilation in asthmatic subjects. Am Rev Respir Dis 1986; 139: 986-989.

42. Jack CIA, Calverley PMA, Donnelly RJ, et al. Simultaneous tracheal and oesophageal $\mathrm{pH}$ measurements in asthmatic patients with gastroesophageal reflux. Thorax 1995; 50: 201-204.

43. Boeree MJ, Peters FTM, Postma DS, Kleibeuker JH. No effects of high-dose omeprazole in patients with severe airway hyperresponsiveness and (a)symptomatic gastrooesophageal reflux. Eur Respir J 1998; 11: 1070-1074.

44. Aubier M, Levy J, Clerici C, Neukirch F, Herman D. Different effects of nasal and bronchial glucocorticoid administration on bronchial hyperresponsiveness in patients with allergic rhinitis. Am Rev Respir Dis 1992; 146: 122126.

45. Zimmerman B, Gold M. Role of sinusitis in asthma. Pediatrics 1991; 18: 312-316.

46. Brugman SM, Larsen GL, Henson PM, Honor J, Irvin CG. Increased lower airways responsiveness associated with sinusitis in a rabbit model. Am Rev Respir Dis 1993; 147: 314-320.

47. Chan CS, Woolcock AJ, Sullivan CE. Nocturnal asthma: role of snoring and obstructive sleep apnea. Am Rev Respir Dis 1988; 137: 1502-1504.

48. White NW, Raine RI, Bateman ED. Asthma and hyperthyroidism. A report of 4 cases. $S$ Afr Med J 1990; 78: 750-752.

49. Dipaolo F, Stull MA. Bronchial carcinoid presenting as refractory asthma. Am Fam Physician 1993; 48: 785-789.

50. Dillon MJ. Rare vasculitic syndromes. Ann Med 1997; 29: 175-179.

51. Wechsler ME, Garpestad E, Flier SR, et al. Pulmonary infiltrates, eosinophilia, and cardiomyopathy following corticosteroid withdrawal in patients with asthma receiving zafirlukast. JAMA 1998; 279: 455-457.

52. Busse WW, Gern JE. Viruses in asthma. J Allergy Clin Immunol 1997; 100: 147-150.

53. Kraft M, Wenzel SE, Bettinger CM, Martin RJ. The effect of salmeterol on nocturnal symptoms, airway function, and inflammation in asthma. Chest 1997; 111: 1249-1254.

54. Cunningham AF, Johnston SL, Julious SA, Lampe FC, Ward ME. Chronic Chlamydia pneumoniae infection and asthma exacerbations in children. Eur Respir J 1998; 11: 345-349.

55. Hahn DL, Bukstein D, Luskin A, Zeitz H. Evidence for Chlamydia pneumoniae infection in steroid-dependent asthma. Ann Allergy Asthma Immunol 1998; 80: 45-49.
56. Busse WW, Kiecolt-Glaser JK, Coe C, Martin RJ, Parker SR. Stress and asthma. Am J Respir Crit Care Med 1995; 151: 249-252.

57. Campbell DA, Yellowlees PM, McLennan G, et al. Psychiatric and medical features of near fatal asthma. Thorax 1995; 50: 254-259.

58. Bosley CM, Fosbury JA, Cochrane GM. The psychological factors associated with poor compliance with treatment in asthma. Eur Respir J 1995; 8: 899-904.

59. Beynon HLC, Garbett ND, Barnes PJ. Severe premenstrual exacerbations of asthma: effect of intramuscular progesterone. Lancet 1988; ii: 370-372.

60. Pauli BD, Reid RL, Munt PW, Wigle RD, Farket L. Influence of the menstrual cycle on airway function in asthmatic and normal subjects. Am Rev Respir Dis 1989; 140: 358-362.

61. Kalkhoveng E, Wissink S, Van Der Saag PT, van der Burg B. Negative interaction between the Rel A (p65) subunit of NF- $\mathrm{KB}$ and the progesterone receptor. J Biol Chem 1996; 271: 6217-6224.

62. Tan KS, McFarlane LC, Lipworth BJ. Loss of normal cyclical beta 2 adrenoceptor regulation and increased premenstrual responsiveness to adenosine monophosphate in stable female asthmatic patients. Thorax 1997; 52: 608-611.

63. Ayres JG, Miles JF, Barnes PJ. Brittle asthma. Thorax 1998; 53: 315-321.

64. Town GI, Allan C. Ventilatory responses to hypoxia and hypercapnia in asthmatics with previous respiratory failure. Aust NZ J Med 1989; 19: 426-430.

65. Kikuchi Y, Okayama H, Okayama M, Sasaki H, Takishima $\mathrm{T}$. Interaction between histamine and vagal stimulation on tracheal smooth muscle in dogs. $J$ Appl Physiol 1984; 56: 590-595.

66. Barnes PJ. Blunted perception and death from asthma. $N$ Engl J Med 1994; 330: 1383-1384.

67. Emery NL, Vollmer WM, Buist AS. Implication of food allergies in the management of asthmatic patients. Am J Respir Crit Care Med 1994; 149: A196.

68. Ernst P, Habbick B, Suissa S, et al. Is the association between inhaled $\beta$-agonist use and life-threatening asthma because of confounding severity? Am Rev Respir Dis 1993; 148: 75-79.

69. O'Driscoll BRC, Ruffles SP, Ayres JG, Cochrane GM. Long term treatment of severe asthma with subcutaneous terbutaline. Br J Dis Chest 1988; 82: 360-367.

70. Sykes AP, Lawson N, Finnegan JA, Ayres JG. Creatinine kinase activity in patients with brittle asthma treated with long term terbutaline. Thorax 1991; 46: 580-583.

71. Baker JC, Tunnicliffe WS, Duncanson RD, Ayres JG. Double blind placebo controlled food challenge in type 1 and type 2 brittle asthma. Thorax 1996; 51 Suppl 3: A2.

72. Barnes PJ, Adcock IM. Steroid-resistant asthma. Q J Med 1995; 88: 455-468.

73. Woolcock AJ. Steroid resistant asthma: what is the clinical definition? Eur Respir J 1993; 6: 743-747.

74. Leung DYM, Martin RJ, Szefler SJ, et al. Dysregulation of interleukin 4, interleukin 5, and interferon $\gamma$ gene expression in steroid-resistant asthma. J Exp Med 1995; 181: 33-40.

75. Barnes PJ, Greening AP, Crompton GK. Glucocorticoid resistance in asthma. Am J Respir Crit Care Med 1995; 152: 125S-140S.

76. Szefler SJ, Leung DY. Glucocorticoid-resistant asthma: pathogenesis and clinical implications for management. Eur Respir J 1997; 10: 1640-1647.

77. Adcock IM, Brown CR, Shirasaki H, Barnes PJ. Effects of 
dexamethasone on cytokine and phorbol ester stimulated c-Fos and c-Jun DNA binding and gene expression in human lung. EurRespirJ 1994; 7: 2117-2123.

78. Adcock IM, Lane SJ, Brown CA, Lee TH, Bames PJ. Abnormal glucocorticoid receptor/AP-1 interaction in steroid resistant asthma. J Exp Med 1995; 182: 1951-1958.

79. Adcock IM, Brady H, Lim S, Karin M, Barnes PJ. Increased JUN kinase activity in peripheral blood monocytes from steroid-resistant asthmatic subjects. Am J Respir Crit Care Med 1997; 155: A288.

80. Cypcar D, Busse WW. Steroid-resistant asthma. J Allergy Clin Immunol 1993; 92: 362-372.

81. Lane SJ, Atkinson BA, Swimanathan R, Lee TH. Hypothalamic-pituitary axis in corticosteroid-resistant asthma. Am J Respir Crit Care Med 1996; 153: 15101514.

82. Synek M, Beasley R, Frew AJ, et al. Cellular infiltration of the airways in asthma of varying severity. Am J Respir Crit Care Med 1996; 154: 224-230.

83. Vrugt B, Djukanovic R, Bron A, Aalbers R. New insights into the pathogenesis of severe corticosteroid-dependent asthma. J Allergy Clin Immunol 1996; 98: S22-S26.

84. Wenzel SE, Szefler SJ, Leung DY, Sloan SI, Rex MD, Martin RJ. Bronchoscopic evaluation of severe asthma. Persistent inflammation associated with high dose glucocorticoids. Am J Respir Crit Care Med 1997; 156: 737743.

85. Jatakanon A, Mohamed JB, Lim S, Maziak W, Chung KF, Barnes PJ. Neutrophils may contribute to the pathogenesis of airway inflammation in steroid-dependent intractable asthma. Am J Respir Crit Care Med 1998; 157: A875.

86. Jonat C, Rahsdorf HJ, Park KK, et al. Anti tumor promotion and antiinflammation: down-modulation of AP-1 (fos/jun) activity by glucocorticoid hormone. Cell 1990; 62: 1189-1204.

87. Yang-Yen H, Chambard J, Sun Y, et al. Transcriptional interference between c-Jun and the glucocorticoid receptor: mutual inhibition of DNA binding due to direct proteinprotein interaction. Cell 1990; 62: 1205-1215.

88. Peters MJ, Adcock IM, Brown CR, Barnes PJ. $\beta$-Adrenoceptor agonists interfere with glucocorticoid receptor DNA binding in rat lung. Eur J Pharmacol (Molec Pharmacol) 1995; 289: 275-281.

89. Adcock IM, Stevens DA, Barnes PJ. Interactions between steroids and $\beta_{2}$-agonists. Eur Respir J 1996; 9: 160-168.

90. Peters MJ, Yates DH, Chung KF, Barnes PJ. $\beta_{2}$-Agonist dose reduction: strategy and early results. Thorax 1993; 48: 1066.

91. Sears MR. Dose reduction of beta-agonists in asthma. Lancet 1991; 338: 1331-1332.
92. Brown JP, Greville WH, Finucane KE. Asthma and irreversible airflow obstruction. Thorax 1984; 39: 131-136.

93. Ulrik CS, Lange P. Decline of lung function in adults with bronchial asthma. Am J Respir Crit Care Med 1994; 150: 629-634.

94. Peat JK, Woolcock AJ, Cullen K. Rate of decline of lung function in subjects with asthma. Eur J Respir Dis 1987; 70: $171-179$.

95. Chu H, Trudeau JB, Szefler SJ, Leung DYM, Martin RJ, Wenzel SE. Collagen deposition in endobronchial biopsy specimens from severe asthmatics as compared to asthmatic and control groups. Am J Respir Crit Care Med 1997; 155: A502.

96. Paganin F, Seneterre E, Chanez P, et al. Computed tomography of the lungs in asthma: influence of disease severity and etiology. Am J Respir Crit Care Med 1996; 153: $110-114$.

97. Haahtela T, Järvinsen M, Kava T, et al. Effects of reducing or discontinuing inhaled budesonide in patients with mild asthma. N Engl J Med 1994; 331: 700-705.

98. Agertoft L, Pedersen S. Effects of long-term treatment with an inhaled corticosteroid on growth and pulmonary function in asthmatic children. Respir Med 1994; 5: 369372.

99. Dompeling E, Van Schayck CP, Molema J, Folgering H, van Grusven PM, van Weel C. Inhaled beclomethasone improves the course of asthma and COPD. Eur Respir $J$ 1992; 5: 945-952.

100. Selroos O, Pietinalcho A, Lofroos AB, Riska A. Effect of early and late intervention with inhaled corticosteroids in asthma. Chest 1995; 108: 1228-1234.

101. Woolcock A, Lundback B, Ringdal N, Jacques L. Comparison of addition of salmeterol to inhaled steroids with doubling the dose of inhaled steroids. Am J Respir Crit Care Med 1996; 153: 1481-1488.

102. Pauwels RA, Lofdahl C-G, Postma DS, et al. Effect of inhaled formoterol and budesonide on exacerbations of asthma. N Engl J Med 1997; 337: 1412-1418.

103. Evans DJ, Taylor DA, Zetterstrom O, Chung KF, O'Connor BJ, Barnes PJ. A comparison of low-dose inhaled budesonide plus theophylline and high-dose inhaled budesonide for moderate asthma. $N$ Engl J Med 1997; 337: 1412-1418.

104. Virchow J, Hassall SM, Summerton L, Klim J, Harris A. Reduction of asthma exacerabtions with zafirlukast in patients on inhaled corticosteroids. Eur Respir J 1997; 10: Suppl 25, 420S

105. Hill SJ, Tattersfield AE. Corticosteroid sparing agents in asthma. Thorax 1995; 50: 577-582.

106. Barnes PJ. New drugs for asthma. Clin Exp Allergy 1996; 26: $738-745$. 